VOL 3 (2019) NO 3

e-ISSN : 2549-9904

ISSN : 2549-9610

\title{
Forecasting Tourist Arrival in the Province of Surigao del Sur, Philippines using Time Series Analysis
}

\author{
Ruby Mae E. Maliberan \#

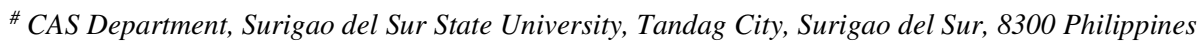 \\ E-mail: malibs_28@yahoo.com
}

\begin{abstract}
The study attempted to forecast the number of tourist arrival in the province of Surigao del Sur using the historical monthly tourist arrival data from 2012-2016 using three time series. Findings showed that the tourist arrival in the province is likely to be increasing. As more foreign and local tourist arrivals are expected as a result of forecast model. Furthermore, it showed that there was a long term increasing trend of the tourist arrival in the province. Results revealed that the Mean Absolute Percentage Error (MAPE) of the forecasted tourist arrival data yielded an error of $11 \%$ which means that predicted data is closer to the actual data. Based on the findings of the study, the researcher recommends that this study can be adapted by other Tourism Office of CARAGA, Philippines.
\end{abstract}

Keywords - Forecasting, Multiplicative Decomposition, Regression, Tourist arrival, Time Series Analysis.

\section{INTRODUCTION}

The tourist arrival in the province of Surigao del Sur, Philippines faces many challenges to retain its top position as one of the main tourist destinations in Mindanao. A drop by 16.9 percent to 45,691 in 2013 from 54,998 in 2012 was observed that affected the local tourism industry. One of the compelling reasons was due to the different typhoons that hit the province particularly in the year 2013 [1]. Another reason that affected the demand for tourist arrival was due to the internal policies of resort owners regarding tour packages. They did not want that tourists to avail the said packages from the local folks serving at a lower price. Although there was an increased number of tourist arrival from 2013 to 2016, however, a drop of 5 percent was again recorded in 2017 due to the declaration of Martial Law by President Rodrigo Duterte [2]. Surigao del Sur is one of the provinces of CARAGA Region blessed with stunning natural wonders and a lot of tourist attractions which is slowly carving a name in the tourism industry on this side of the country. It has two cities and 17 municipalities nearly all are situated in the coastal vicinities with Tandag as its capital. It has three major attractions. Tinuy-an Falls, known as the little "Niagra Falls of the Philippines," Enchanted River, a placid blue water which allows viewing of beautiful fishes underneath and Britania Islets which are endowed with pristine white beaches and crystal clear blue waters teeming with coral and marine life.
The significant increase of tourist arrival from 2013 to 2016 is an indication of healthy tourism industry in the province. However, resort owners do not have the correct procedure for estimating the monthly tourist arrivals which sometimes leads to poor customer services and even bankruptcy. Thus, there is a need to forecast the foreign and local tourist arrivals so that the projected figure could be a basis for proper scrutiny and planning. This can aid in catering their needs regarding hotel accommodations, food preparations, recreational and other activities related to tourism industry. Moreover, this figure could also be used to encourage social, economic and physical development in the province [3]. Hence this study attempted to predict the tourist arrivals in the province of Surigao del Sur, Philippines.

\section{REVIEW OF RELATED LITERATURE}

This section presents the review of related literature of the study which is derived from articles, journals, paper and dissertation through a review made by the researcher. The framework of this study employs time series analysis in predicting tourists arrival using historical monthly data from 2012 to 2016. The tourism industry development has been the main provider to improve related economic activities all over the U.S. and the world as well. It has generated job in small and large societies, and it is the main business in several places. It is the leading financial activity in several societies. However, the importance of tourism industry to society is not extensively implicit. Majority of people 
believe of tourism industry regarding its economic impacts, taxes and jobs. Yet, the impact from tourism is wide and frequently controls areas afar those generally related with tourism. Stakeholders including residents who comprehend the possible impact of tourism industry can incorporate this business into their society in the most optimistic approach.

Tourism industry is described as a vital division that has a significant impact on the progress of country's market [4]. The core advantage of the tourism industry is earnings formation and job creation. For many countries and regions, it is the main source of benefit. The capacity of the state economy to profit from tourism industry relies on the accessibility of asset to extend the needed infrastructure and on its capability to provide the desires of tourists.

Meanwhile, [5] signifies tourism in the framework of modern society. The study aimed at the examination of the numerous relations and insinuations of the tourism industry in the financial field, and the issues that measure the level to which tourism industry adds to the market of a target. The author presented how tourism industry influenced, through its actions and growth, both the human and material element, and explained the favourable outcomes of tourism on the intrusion areas, performing as a part that motivates improvement and economic improvement. To exemplify these features, the author showed an investigation of a micro-destination like Romania, stressing all the constitutive fundamentals of the objective and how they work together with local and national economic organizations.

According to [6], tourism business is the major important type of industry and main sector of income in Nepal. The main reason of tourist visit in Nepal is holiday/pleasure, business, trekking \& mountaineering, and official. It was able to produce employment opportunities to the people of Nepal.

According to [7], one of the relative asset of the Philippines as a tourist attraction is its good suite of eyecatching natural and cultural heritage wealth and resources. This advantage, including with other optimistic attributes, guides partners in cultivating an environmentally and socially accountable tourism program that brings better, more extensively dispersed earnings and employment opportunities.

Tourism Industry is a significant business in the Philippines since it offers a straight source of income to the nation. It is an important provider to the economy, counting to 5.8 percent of gross value to the GDP from 2000 to 2010 , and produces income from revenue, foreign exchange, and employment. On the other hand, tourism industry is the main employment producer in the country. Tourism industry rapidly generates income both for large and small establishments and businesses, for families through salaries from tourism-related jobs and the government through tax revenues. The proceeds collected by the Philippine government provide services, activities, and goods used by tourists. The flow of employment in tourist-converged areas encourages occupational and skills development unwraps prospects for young people to increase knowledge and experiences and permits the administration to export outstanding services [8].

It was noted by [9] that tourism can play a major role in stimulus programs because of its ability to create jobs.
Tourism industry is significant to people since it is the main job producer as a labor-accelerated industry. For one, the tourism and travel business is composed of 1.4 million jobs which account for $4.1 \%$ of employment in the financial system of the Philippines. Tourism is a major dollar earner. Former Tourism Secretary Jimenez described the Philippines as one of the best-ranked destinations by the World and Trade Tourism Council. It is ranked 67 among 184 nations, signifying that tourism industry is one of the main sources of income in the Philippines.

The same committee said visitors from other countries spent P256-B in 2014 here characterizing $69 \%$ of the country. Tourism openly provides work for 4.9 million Filipinos comprising roughly $11 \%$ of the overall employment not including the meandering workforce in the food and drink providers to the business. Thus, tourism industry is the fifth major firm business. Moreover, tourism industry is ranked also as the third leading dollar collecting industry next to the Business Process Outsourcing (BPO).

There have been different forecasting methodologies used by the researchers in the past. Some of these techniques were ARIMA (Autoregressive Integrated Moving Average), Neural Networks, Regression Analysis, SARIMA (Seasonal Autoregressive Integrated Moving Average), and Exponential Smoothing and Time Series Analysis. These techniques are potential tools to determine the tourist arrival behavior in Surigao del Sur. [6] tried to model the tourist arrival in Nepal using the monthly time series data from 1991 to 2011 using Seasonal Auto-Regressive Integrated Moving Average (SARIMA). [3] attempted to quantify and evaluate the capability of prediction with ARIMA and ARFIMA models, Exponential Smoothing, using $\mathrm{R}$ Language. [10] Stated that the time series models had been extensively utilized in tourism demand prediction in the past with the influence of the integrated autoregressive movingaverage models.

Although it was found from the cited studies that SARIMA model was the best model to forecast tourist arrivals. Mean Absolute Percentage Error (MAPE) is one of the bases in measuring its accuracy. In that study, MAPE was 9.38 percent [6]. This implies that the model used is somewhat less accurate. Forecasting accurate tourism demand enhances the effectiveness of businesses sector, strengthen economies and augment earnings of the people [11].

[12] Discussed in their study that a model which can do temporary predictions on tourist arrivals and can measure macroeconomic shocks from the origin country could be a good approach to forecasting future tourism demand. Another operating model can also be offered by ARIMA which exceeds exponential smoothing models in a one year forecasting out of sample forecasts.

In particular, time series analysis predicts tourist arrivals by considering past patterns. Numerous researches have been published in the field of tourists arrival in current years. Administrators usually adopt policies that are scientifically developed and thus maintain viability [13]. In the case of tourism, the sector provides considerably to the trade and industry of many countries and regions.

[14] Even sided with the science of forecasting because it is so important. This is also supported by [15] who associate 
planning and forecasting as fundamental of rational decision-making. The same is true when it comes to tourism, the need to plan requires the need to obtain reliable future events, thus the need to forecast tourist arrival.

\section{System Architecture}

This section outlines the essential elements which serve how the monthly tourist arrival is forecasted. Historical Monthly tourist arrival data is collected from 2012 to 2016 from the office of Provincial Tourism in Surigao del Sur. Moving Average is applied in order to smooth the data. This is the second stage of forecasting the data. The third box is extracting seasonal and irregular data component. This means that peak and lean season on the arrival of tourist is being computed and extracted out from the baseline which is the moving average. This next box is getting the seasonal index. Since the researcher is forecasting tourist arrival by month and there are twelve months in a year. It means that there are also twelve seasonal index that must be computed for one year. The next step is to deaseasonalize the data. This is done by dividing the original data which is the monthly tourist arrival by the seasonal index. The next step is finding the trend component of the tourist arrival using simple linear regression. Simple Linear Regression is used in order to determine if there is a trend that exists based on the characteristics of the data. The seventh box is applying the multiplicative decomposition model. Once the trend is already calculated, the monthly tourist arrival forecasted is calculated using multiplicative Decomposition model.

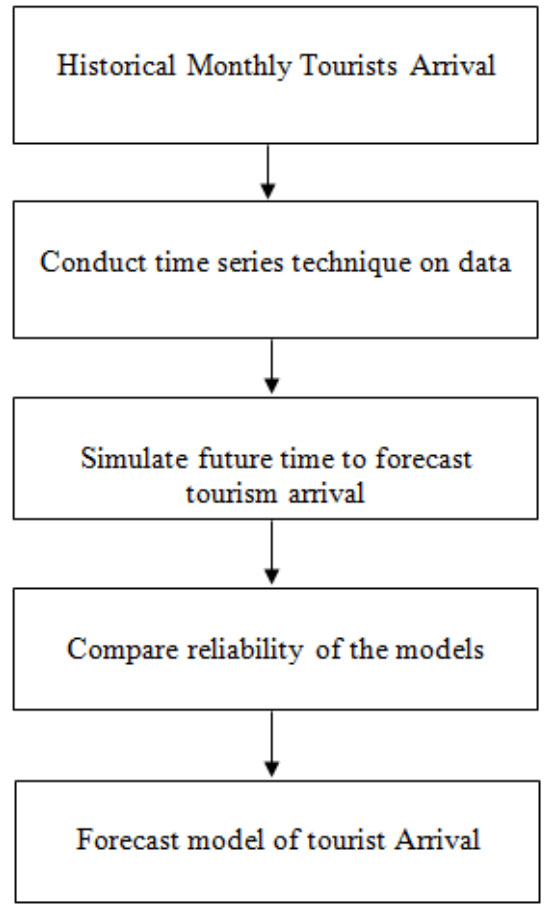

Fig. 1 System Architecture

\section{THE MATERIAL AND METHOD}

This section includes the research design, tools, and techniques in gathering necessary data and proper statistical treatment to attain appropriate results and findings.

\section{A. Research Design}

The study employed the time series analysis as a tool in forecasting the tourist's arrival in the province of Surigao del Sur. The researcher aimed at gathering accurate historical monthly tourist arrival data that will be used to predict tourists' arrival using a Time Series Analysis. Its generated output was used for some statistical calculations. There were no more research respondents and questionnaires developed since the study used the secondary data.

Time series plots can tell blueprints such as trends, random, period or cycles, level shifts, combination of patterns or unusual observations. A time series model describes a variable related to its own history and a random disorder term. Specific consideration is paid to investigating the historical patterns and trends (such as seasonality) of the time series involved, and to forecast the future of this series found on the patterns and trends identified in the model. Because time series models only need historical knowledge of a variable, it is reasonable in model estimation and data gathering [16].

It is also important to consider the accuracy of the forecasting model. The Mean Absolute Percentage Error (MAPE) is gauge of the forecasting precision of the Time Series Analysis. Thus, the lesser the MAPE means, the more accurate the forecasting model is. Hence the primary focus of this study is to forecast the tourist arrival will be using time series analysis with a higher accurate level and with a lesser percentage error [17].

The moving-average technique is not only helpful in smoothing a time series to see its trend. It is the fundamental technique utilized in computing the seasonal fluctuation. The moving-average approach simply smooths the variations in the data. This is achieved by moving the arithmetic mean values through the time series model. In applying the moving-average approach to a time series model, the data must follow a kind of linear trend and have a specific rhythmic pattern of variations. On the other hand, time linear regression is a basic and commonly used type of predictive data analysis. In particular, the concept of linear regression is to check whether a set of predictor variables do a right job in forecasting an outcome variable.

\section{B. Research Locale}

The study was conducted in the Province of Surigao del Sur as shown in Figure 2. The province of Surigao del Sur is found in the CARAGA region in the eastern part of Mindanao. Tandag city is its capital town and borders Davao Oriental to the south, Agusan del Norte and Agusan del Sur to the west, and Surigao del Norte to the north. It is positioned at the eastern shore of Mindanao facing the Philippine Sea. The province is terrestrially situated on the Northeastern shore of Mindanao facing the Pacific Ocean. The province consists of two cities and 17 municipalities nearly all of which are found in the coastal areas. These municipalities are partitioned into 314 barangays and have two legislative districts

Presented in Figure 2 is the map of the Province of Surigao del Sur, Philippines and its neighboring Region in CARAGA in which monthly tourist arrival was collected from the year 2012 up to 2016. 


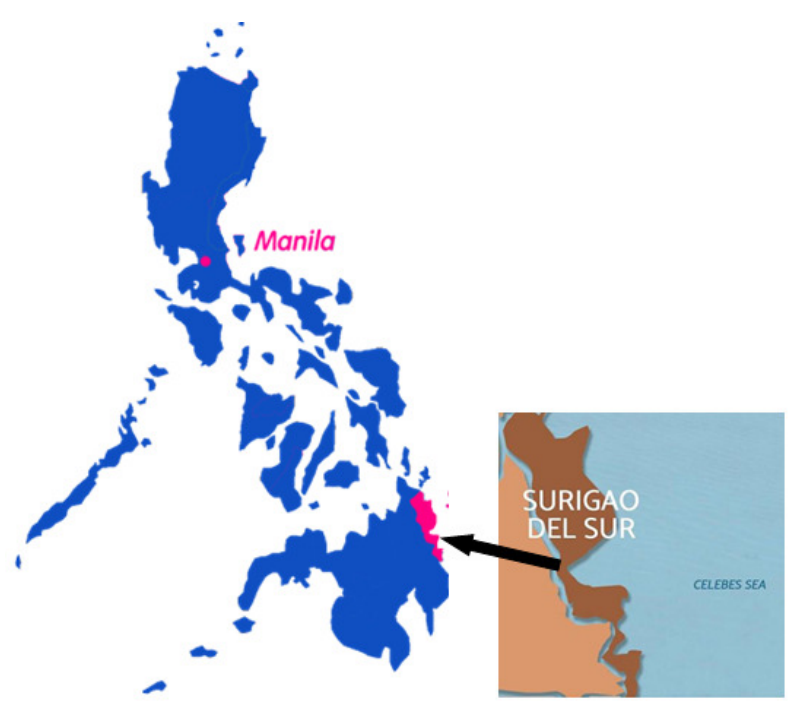

Fig. 2 Map of Surigao del Sur

\section{Data Collection}

The researcher asked the assistance of the Provincial Tourism office in data gathering. The municipal tourism office had provided a copy of historical tourist arrivals to the Provincial Tourism Office they gathered from their respective tourist spots thus maintaining the accuracy and the integrity of the data being collected by the researcher. Furthermore, the Provincial Tourism office has all the records of tourists' activities from the different tourist spots in the whole province of Surigao del Sur, Philippines.

Forecasting of tourist arrivals requires a higher frequency of data such as daily, monthly and even quarterly to analyze the movement of data. The researcher has chosen the monthly tourists' arrival since this frequency will best provide the possibility of modeling and forecast the variation pattern or the trend of tourists' arrival.

The Provincial Tourism Office used the monthly tourist arrival in a year. This means that every year, there were twelve (12) sets of tourists' data. By gathering tourist's arrival data from 2012-2016, a chronological record of the tourism visits found available thus historical time series of data. Moving average was applied as part of pre-processing technique because tourists arrival data followed a linear trend and had a specific fluctuation pattern. This technique was utilized to smooth a time series tourists arrival data to see the trend.

\section{Statistical Tools}

The historical monthly tourist arrival data from 20122016 was collected and analyzed using the Moving-average method and Time Linear Regression which are part of a Time Series Analysis. The moving-average method is not only helpful in leveling a time series; it is the basic method used in measuring the seasonal fluctuation. Time Linear regression was used to determine if there is a trend that exists based on the characteristics of the historical tourist arrival data in the form of

$$
\text { arrival }=\beta_{0}+\beta_{1} \text { Time }+\varepsilon
$$

\section{RESUlTS AND DISCUSSION}

This section presents the results of the study conducted. The first section presented how the time series behavior is determined. The next section discussed how the forecasting model was developed and the last section presented how tourist arrival in Surigao del Sur was quantified.

\section{A. Determining Time Series Behavior of the Tourist Arrival}

The actual data which was used by the researcher in determining the time series behavior of the tourist arrival is presented in Table 1.

TABLE I

ACtUAL HistoricAl TOURISTS ARRIVAL DATA From 2012-2016

\begin{tabular}{|c|c|c|}
\hline Year & Month & Actual Data \\
\hline \multirow{12}{*}{2012} & January & 2014 \\
\hline & February & 1796 \\
\hline & March & 6313 \\
\hline & April & 6512 \\
\hline & May & 6778 \\
\hline & June & 5751 \\
\hline & July & 4747 \\
\hline & August & 6623 \\
\hline & Sept & 4763 \\
\hline & October & 5740 \\
\hline & November & 2508 \\
\hline & December & 1453 \\
\hline \multirow{12}{*}{2013} & January & 2969 \\
\hline & February & 3078 \\
\hline & March & 3951 \\
\hline & April & 5558 \\
\hline & May & 5362 \\
\hline & June & 5016 \\
\hline & July & 3437 \\
\hline & August & 3537 \\
\hline & Sept & 3535 \\
\hline & October & 3717 \\
\hline & November & 2875 \\
\hline & December & 2656 \\
\hline \multirow{12}{*}{2014} & January & 2733 \\
\hline & February & 3426 \\
\hline & March & 3557 \\
\hline & April & 6569 \\
\hline & May & 6975 \\
\hline & June & 6034 \\
\hline & July & 5853 \\
\hline & August & 6434 \\
\hline & Sept & 6977 \\
\hline & October & 9081 \\
\hline & November & 8333 \\
\hline & December & 3594 \\
\hline
\end{tabular}




\begin{tabular}{|c|c|c|}
\hline Year & Month & Actual Data \\
\hline \multirow{12}{*}{2015} & January & 3048 \\
\hline & February & 3563 \\
\hline & March & 4629 \\
\hline & April & 7168 \\
\hline & May & 7781 \\
\hline & June & 7183 \\
\hline & July & 5825 \\
\hline & August & 6470 \\
\hline & Sept & 6884 \\
\hline & October & 8041 \\
\hline & November & 8568 \\
\hline & December & 4349 \\
\hline \multirow{12}{*}{2016} & January & 3537 \\
\hline & February & 4062 \\
\hline & March & 4879 \\
\hline & April & 7625 \\
\hline & May & 8072 \\
\hline & June & 9780 \\
\hline & July & 9050 \\
\hline & August & 8059 \\
\hline & Sept & 8296 \\
\hline & October & 11193 \\
\hline & November & 4482 \\
\hline & December & 2918 \\
\hline
\end{tabular}

It can be observed that tourist arrival dropped by 16.9 percent to 45,691 in 2013 from 54,998 in 2012. Figures went up from 45,691 in 2013 to 69,566 in 2014 or at an increase of 34.3 percent. It continued to increase to about 5.36 percent in 2015 with a total of 73,509 arrivals recorded. In $2016,81,953$ tourist arrival was recorded or at an equivalent increase of 10.3 percent. The increasing trend of the tourist arrival in the province could be attributed to the continued effort of the Office of Tourism to promote the different tourist spots of Surigao del Sur through promotional items, advertisement in local newspapers and social media. The government of Surigao del Sur is also trying its best to improve the roads that connect to these major tourist destinations such as Laswitan Lagoon, Britania Islands, Enchanted River, and Tinuy-an Falls. The historical data showed that there was indeed a time trend effect on the series when simulated using the forecasting model. Moreover, there is a statistical linear effect on the data.

\section{B. Development of the forecast model}

Upon plotting the historical monthly data, moving average was applied. Moving average techniques forecast demand by calculating an average of actual demands from a specified number of prior periods. This is done by getting the average of all the months in a year to every month of each year. The next step was getting the seasonal and irregular component. This means that peak and lean season on the arrival of tourist is being computed and extracted out from the baseline which is the moving average. Seasonal and irregular data were calculated by dividing the actual data to the moving average.
All seasonal and irregular components of the same month from 2012 to 2016 are then consolidated by finding its average. Then deseasonalized data was computed by dividing the average seasonal index to the actual data. After getting the deseasonalized data, trend can already be calculated using simple linear regression. time linear regression used able to determine trend $t$ on the characteristics of the data.

The result showed that the actual data from the month of January in 2012 which is 2,014 tourist arrivals is closer to the forecast data for that period which is 2,199 . It has a MAPE error of 9.22 percent. The reason for the increase of tourist arrival aside from the scenic tourist spots in the province is due to the continued advertisements of both the resort owners and the Office of Tourism in radio, newspapers and social media. In order to develop a forecasting model, it is important to consider the behavior of data whether it is stationary or non stationary. Since all the components of the time series is evident in the data, the researcher had applied a time series forecasting model. Historical monthly tourist arrival data is collected from 2012 to 2016 from the office of Provincial Tourism in Surigao del Sur, Philippines.

\section{Test for Significance of Regression}

Simple Linear regression is used in order to determine if there is a trend that exists based on the characteristics of the data. Using the data for tourism arrival the forecast model using time linear is arrival $=3533+52.6$ time $*$

The result of testing is done by comparing the actual number of tourist arrival from 2012 to 2016 with the result of the forecasted value for the said years. The overall forecast tourist arrival data from the time series model yielded an error of $11 \%$ using MAPE. For example in the month of January 2016, its actual tourist arrival data is 3,537 and its the forecast data is 3,725. MAPE is computed by subtracting projected data from the actual data and dividing it by the actual data. This yields a $5.3 \%$ error for that particular period. Getting the forecasting error is important because it implies the accuracy of the model being used in the study.

D. Quantifying Tourist Arrival in Local Economy of Surigao del Sur

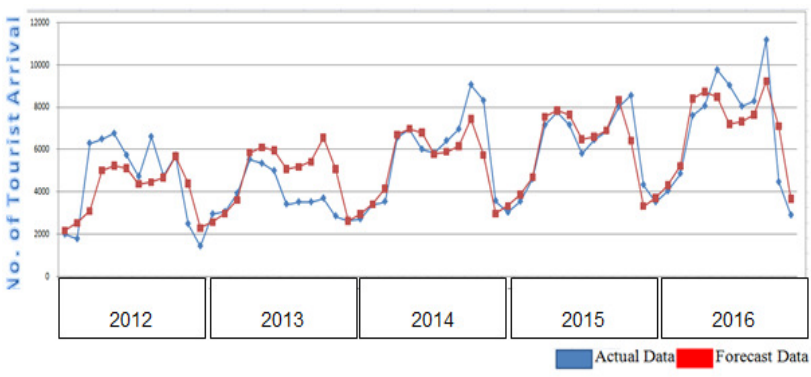

Fig. 3 Simulation Result of the actual and forecast tourism demand in both foreign and local tourists from 2012 to 2016.

Shown in Figure 3 is a graphical presentation of the actual and forecast monthly tourist arrival in both foreign and local tourist arrival from 2012 to 2016 . The blue line represents the actual data, and the red line represents the forecast data. It can be observed that there was a slight difference between the forecast data and the actual data in 2013 particularly in 
October, November, and December. This is because there was an unexpected dropped of tourist arrival in that period due to typhoons Vinta and Zoraida that hit the province in that period.

Figure 4 and Figure 5 also show also the forecast tourism demand in both foreign and domestic from 2012 to 2016.

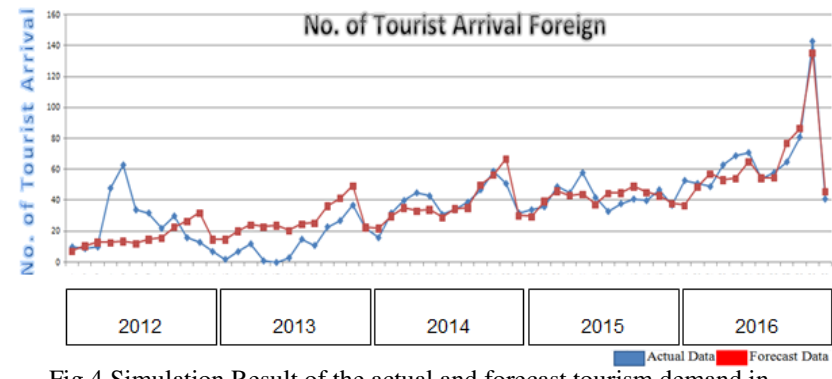

Fig.4 Simulation Result of the actual and forecast tourism demand in foreign tourists from 2012 to 2016

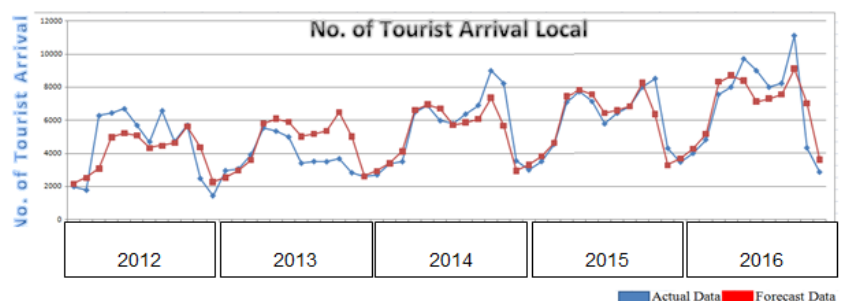

Fig.5 Simulation Result of the actual and forecast tourism demand in local tourists from 2012 to 2016 .

Table 2 and Figure 6 showed the Five (5) year monthly forecast of the number of tourist arrival from 2017 to 2021. It is evident that by 2021 , there would be 1,365 foreign tourists and 119,445 local tourists or a total of 120,910 tourists who are expected to visit the province of Surigao del Sur.

TABLE II

FIVE YEAR MONTHLY FORECAST OF TOURISTS ARRIVAL FROM 2017 TO 2021

\begin{tabular}{|c|c|c|c|}
\hline Year & Foreign & Local & Total \\
\hline 2017 & 845 & 88,109 & 88,997 \\
\hline 2018 & 975 & 95,943 & 96,975 \\
\hline 2019 & 1,105 & 103,777 & 104,953 \\
\hline 2020 & 1,235 & 111,611 & 112,932 \\
\hline 2021 & 1,365 & 119,445 & 120,910 \\
\hline
\end{tabular}

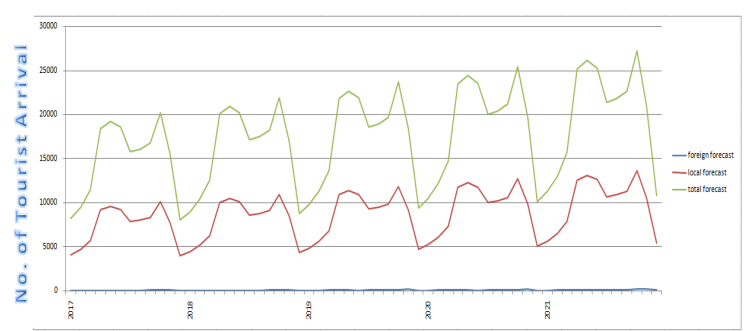

Fig.6 The Simulation Result of the total number of tourists arrival from 2017 to 2021
TABLE III

TOP 3 FOREIGN TOURIST ARRIVALS FROM 2012-2016

\begin{tabular}{|c|c|}
\hline Country & Arrival \\
\hline China & 348 \\
\hline USA & 340 \\
\hline Australia & 205 \\
\hline
\end{tabular}

Table 3 showed the top 3 countries where foreign tourists came from who visit the province of Surigao del Sur. It can be observed that China is the leading country of origin of tourists visiting the province. USA and Australia followed next.

\section{CONCLUSION}

The study was able to predict the number of tourist arrival in the province of Surigao del Sur. It generated a graphical presentation of the actual historical monthly tourist arrival data and the projected tourist arrival data from year 2012 to 2016. It was also able to forecast both the foreign and domestic tourist arrival from 2017 to 2021.

Time Series Analysis, moving average method and multiplicative decomposition model are effective forecast technique to determine tourist arrivals. The Mean Absolute Percentage Error (MAPE) which is $11.0 \%$ only showed that forecasting tourist arrival data is closer to the actual data and therefore the model used in forecasting is accurate.

\section{RECOMMENDATION}

The researcher would like to recommend that this study can be adapted by other Tourism Offices not only in CARAGA but also in other provinces throughout the Philippines as basis for their development plan. Resort owners can also use the forecasting tool to help them forecast the arrival of their guests in both foreign and domestic in the years to come. The forecast data could be a basis for proper planning that will improve their services particularly in the accommodation and preparation of food. Other statistical models can also be incorporated to the existing model to improve the model accuracy

\section{REFERENCES}

[1] P. Esmaquel, Signal 3 over Surigao del Sur, Rappler. Retrieved 2 March 2018, from https://www.rappler.com/nation/specialcoverage/weather-alert/17163-signal-no-3-over-surigao,-5-others, 2013.

[2] K. Canedo, Tourist Arrival in Davao City down by 19 percent. SunStar Davao. Retrieved 1 March 2018, from http://www.sunstar.com.ph/davao/local news/2017/07/26/touristarrivals-davao-city-down-19-555023, 2017.

[3] K. Mansor, and W. Ishak, Forecasting Tourist Arrivals to Langkawi Island Malaysia, Cross-Cultural Management Journal, vol. 17, no. 1, 2015 .

[4] X. Agaraj, and M. Murati, Tourism an Important Sector of Economy Development. Annals of The Constantin University Of Economy Series, vol. 25, no. 3, pp. 755-760, 2009.

[5] C. Bunghez, The Importance of Tourism to a Destination's Economy. Journal of Eastern Europe Research In Business \& Economics, vol. 2, no. 3, pp. 105-110, 2016.

[6] S. Shakya, An Empirical Research on Monthly Tourism Forecasting for Nepal. Research Gate, vol. 28, no. 2, pp. 205-210, 2016.

[7] R. Jimenez, ASEAN Tourism Strategic Plan, 2014-2025 [Ebook]. Quezon City: Department of Tourism (DOT), 2014. 
[8] R. Paje, National Ecotourism Strategy \& Action Plan 2013-2022 [Ebook]. Quezon City: Department of Tourism (DOT), 2014.

[9] B. Marcos, The Importance of Tourism for the Philippines. Bongbong Marcos. Retrieved 1 March 2018, from https://www.bongbongmarcos.com/news/post/the-importance-oftourism-for-the-philippines/, 2010.

[10] H. Song, and G, Li, Tourism Demand Modelling and Forecasting - A Review of Recent Research. Tourism Management, vol. 29, pp. 203 220, 2008.

[11] S. Goyal, and M. Kumar, Towards Tourism Demand Forecasting Methods Elements. Research Notes In Information Science (RNIS), vol. 1 , no. $4,2013$.

[12] D. Gounopoulos, D. Petmezas, and D. Santamaria, Forecasting Tourist Arrivals in Greece and the Impact of Macroeconomic Shocks from the Countries of Tourists' Origin. Annals of Tourism Research, vol. 39, no. 2, pp. 641-666, 2012.
[13] H. Song, G. Li, S. Witt, and G. Athanasopoulos, Forecasting Tourist Arrivals using Time Varying Parameter Structural Time Series Models. International Journal of Forecasting, vol. 27, no. 3, pp. 855869, 2011.

[14] S. Shakya, An Empirical Research on Monthly Tourism Forecasting for Nepal. Research Gate, 28(2), 205-210. 2016.

[15] D. C. Montgomery, C. Jennings, and M. Kulahci, Introduction to Time Series Analysis and Forecasting. WILEY, 2015.

[16] E. Kim, A. Sungil, and H. Kim, A New Metric of Absolute Percentage Error for Intermittent Demand Forecasts. International Journal of Forecasting, vol. 32, no. 3, pp. 669-679, 2016.

[17] R. Tofallis, A Better Measure of Relative Prediction Accuracy for Model Selection and Model Estimation, Journal of the Operational Research Society, vol. 66, no. 8, pp.1352-1362, 2015. 